\title{
Wet granulation in laboratory scale high shear mixers: Effect of binder properties
}

\author{
T.M. Chitu ${ }^{\text {a,* }}$, D. Oulahna ${ }^{\text {a, }}$ M. Hemati ${ }^{\text {b }}$ \\ ${ }^{a}$ RAPSODEE Research Centre, UMR EMAC-CNRS 2392, Ecole des Mines d'Albi-Carmaux, Campus Jarlard, 81013 Albi, France \\ ${ }^{\mathrm{b}}$ Laboratoires de Génie Chimique UMR-CNRS 5503, ENSIACET, INPT, BP 1301, 5 Rue Paulin Talabot, 31106 Toulouse Cedex 1, France \\ Corresponding author at Rapsodee IMT Mines-Albi (oulahna@mines-albi.fr)
}

A B S T R A C T

Keywords:

High shear mixer granulator

Torque curves

Work of adhesion

Viscosity

Scale-up

\begin{abstract}
The effect of binder properties on torque curves, granule growth kinetics, wet mass consistency and dry granule strength has been investigated in this study. Granulation runs have been performed on a fine cohesive microcrystalline cellulose powder (Avicel $105, \mathrm{~d}_{50}=20 \mu \mathrm{m}$ ) in two types of laboratory high shear mixers: a MiPro high shear mixer using a $1.9 \mathrm{~L}$ bowl and a $6 \mathrm{~L}$ Diosna high shear mixer. Binders used included ultra-pure water and solutions of varying concentrations of PVP and HPMC allowing us to cover different values for parameters like viscosity and work of adhesion. Torque curves recorded during granulation are found to allow good control of the process. Optimum liquid requirement for granulation has been found to vary with binder type and decrease with increasing viscosity while granule growth kinetics has been found to be to be related to the work of adhesion for low viscosity binders. Granule strength has been evaluated for wet granules by the means of wet mass consistency measurements on a mixer torque rheometer and for dried granules by means of uniaxial compression tests on a Texture Analyser mechanical testing machine. For low viscosity binders both wet mass consistency and dry granule strength have been found to depend on the work of adhesion. For high viscosity binders higher wet mass consistencies but lower dry granule strengths have been observed. Granulating on the larger $6 \mathrm{~L}$ scale has shown that constant impeller tip speed offers good agreement in terms of mean granule size however granule size distribution seems to be scale dependant.
\end{abstract}

\section{Introduction}

High shear granulation allows converting fine cohesive powders into strong, dense agglomerates named granules. It relies on intimate contact between the mass of fine particles and the binder mass, facilitated by the agitation imposed by an impeller turning at moderate to high speeds. Wetted powder particles are mixed, densified and agglomerated under the action of shearing and compaction forces imposed by the impeller. High shear mixers are often equipped with additional, smaller chopper blades turning at high speeds cutting down large agglomerates that can form in the process. This study focuses on granulation in this type of mixers.

Wet granulation can be seen as a combination of three rate processes as defined by Iveson et al. [1]: wetting and nucleation as the binder is distributed in the powder mass forming initial nuclei, consolidation and growth as collisions between granules as well as granules and initial powder particles lead to increased compaction and granule size, and attrition and breakage as granules deform or break under the action of shearing and impact forces. These processes control final granule properties and depend on the chosen formulation as well as imposed operating conditions. Physico-chemical properties of primary particles and binder determine surface wetting, spreading, adsorption and solid bridge strength [2].

Torque measurements during high shear granulation have allowed relationships between inflection points on the torque curves and states of liquid saturation in the mixer, according to Leuenberger et al. [3]: pendular state when particles are held together by a liquid bridge at their contact points, capillary state that occurs when all the voids are filled with the liquid and the surface liquid is drawn back into the pores under capillary action and funicular state as a transition state between the pendular and capillary states where the voids are not fully saturated with liquid. Following the torque curve the optimum liquid amount is supposed to be found in the third (plateau) phase while increased binder addition endangers overwetting and uncontrollable growth.

The addition of the binder in the process can be achieved either by adding a liquid binder, characterized by a certain viscosity, surface tension and contact angle or by adding a low viscosity liquid like water onto a powder mix comprised of the powder to granulate and a solid binder that dissolves in the low viscosity liquid changing its properties. The binder may also be added as a dry powder in the powder mix and liquefied by increasing temperature up to its melting point. Adding the binder as a dry powder allows the granulation with high viscosity binders without using dedicated pumps or clogging the nozzles and for some high viscosities it might even be the only solution. Our study will present observations carried out using the first method where aqueous binder solutions are prepared and characterized before the granulation process. 
The viscosity of the binder is important in understanding the granulation mechanisms involved and the strength of the resulting granules. Keningley et al. [4] found a minimum binder viscosity associated with granulating non-porous calcium carbonate particles with silicone fluids. They found that in order to successfully form granules a minimum viscosity of $10 \mathrm{mPa}$ s was necessary for mean particle sizes of $8 \mu \mathrm{m}$, of $100 \mathrm{mPa}$ s for particles with a mean size of 50 to $80 \mu \mathrm{m}$ and of 1 Pa s for particles presenting a mean particle size of $230 \mu \mathrm{m}$. Several authors have shown (Johansen and Schaefer [5], Mills et al. [6]) that an increase in viscosity has a benefic effect on granulation up to a certain critical value above which the opposite effect is observed.

Binder viscosity as discussed by Mills et al. [6] is shown to impact granulation mechanisms. Granulation at low viscosities is believed to be controlled by layering growth mechanisms while at higher viscosities coalescence was considered the predominant mechanism based on the absence of layered material, a smaller sphericity and a slow growth consistent with growth by coalescence.

The influence of surface tension has been investigated by Capes and Danckwerts [7]. They found that a minimal surface tension was necessary in order to favor agglomeration. Iveson et al. [8] found that:

- decreasing binder surface tension can lead to a decrease in the dynamic yield stress in the agglomerate

- but that for higher viscosities binder viscosity dominated the wet granule dynamic yield stress.

Ritala et al. [9] found that power consumption of the granulator increases with increasing binder surface tension.

Ennis et al. [10] studied the coupled effect of viscosity and surface tension. They found that the granulation mechanisms depend essentially on the competition between the capillary and viscous forces. They defined a viscous capillary number relating these forces:

$C a_{v i s}=\frac{\mu_{L} U}{\gamma_{L}}$

Where $U$ is the speed of the particles, $\mu_{L}$ is the binder viscosity and $\gamma_{L}$ is the liquid surface tension.

They found that:

- If $C a_{v i s}<10^{-3}$ the energy dissipation due to the viscosity can be neglected compared to the capillary forces and that adhesion is the product of interfacial forces

- If $C a_{v i s}>1$ the viscous force is dominant over the static forces.

Like Ennis, Benali et al. [11] investigated the wet granulation of microcrystalline cellulose by defining a modified capillary number as:

$C a^{*}=\frac{\mu_{L} \omega}{\gamma_{L}(1+\cos \theta)}$

Where the liquid surface tension is replaced by the work of adhesion and the speed of the particles was approximated as the impeller tip speed. They found that for values of the modified capillary number above a value 1.62 the viscous forces predominate and control granule growth while for values below unity the interfacial forces are dominant since increasing the work of adhesion enhances the growth kinetics. They also found that granule friability increases with decreasing viscosity for values of the modified capillary number above unity. We chose to use this definition for our study.

Malamataris and Kiortsis [12] have shown for two substrates (lactose and sulfadiazine) that for comparable values of viscosity (using isopropanol, water and light liquid paraffin as binders) both liquid requirement for the funicular agglomeration state as well as wet deformational behavior is related to the work of adhesion for similar values of viscosity.

The aim of this study is to better understand the relationship between the physico-chemical properties of the powder binder couple and their effects on wet mass rheology, granulation kinetics, wet mass consistency and dry granule strength.

\section{Materials and methods}

\subsection{Materials}

The model product chosen for this study was a microcrystalline cellulose (MCC) powder, MCC Avicel 105 (FMC Biopolymer, Ireland). It presents high cohesion and poor flowing characteristics being an interesting candidate for size enlargement operations [13]. The binders used are aqueous solutions of Polyvinylpirrolidone (PVP10, Sigma Aldrich), Hydroxy-Propyl-Methyl-Cellulose (HPMC, Sigma Aldrich). Some relevant properties for these materials are presented in Table 1. Solution percentages are calculated on weight basis. Contact angle values were obtained by the dynamic capillary rise method on a GBX Instrument balance. Binder viscosity was obtained using a Haake Rheostress RS 600 rheometer. For the non-Newtonian binder solution like HPMC 3\%, variations are observed in viscosity depending on shear rate, the value at $1047 \mathrm{~s}^{-1}$ has been chosen to represent the binder viscosity.

\subsection{Granulation equipment}

\subsubsection{The Mi-Pro ${ }^{\circledR}$ high shear mixer}

The Mi-Pro (Pro-C-Ept, Zelzate, Belgium) high shear mixer (Fig. 1) allows granulating while recording real time impeller torque values within $1 \mathrm{~s}$ intervals. Torque curves allowed us to determine the transition between saturation stages of the wet system applying the method described by Leuenberger et al. [14] by drawing tangents the torque curve while offline microscopic observations allowed us to link these changes in torque evolution to growth mechanisms [13]. Granulation time was of about $14 \mathrm{~min}$ during which the powder bed was homogenized by dry mixing for 2 min before the liquid binder addition was done at a constant rate using a Dosimat 760 syringe pump (Metrohm, Berchem, Belgium).

Representative samples of solid removed from the granulator were tray-dried at $40{ }^{\circ} \mathrm{C}$ for $24 \mathrm{~h}$. Due to the small size of the mixer bowls each sample was taken from a new batch with experiments being

Table 1

Physico-chemical characteristics of binder solutions, contact angle and microcrystalline cellulose Avicel 105.

\begin{tabular}{|c|c|c|c|c|}
\hline Binder properties & $\begin{array}{l}\rho_{\mathrm{L}} \\
\left(\mathrm{kg} / \mathrm{m}^{3}\right)\end{array}$ & $\begin{array}{l}\gamma_{\mathrm{L}} \\
(\mathrm{mN} / \mathrm{m})\end{array}$ & $\begin{array}{l}\mu_{\mathrm{L}}(\mathrm{mPa} \mathrm{s} \\
\left.\text { at } 25^{\circ} \mathrm{C}\right)\end{array}$ & $\theta\left({ }^{\circ}\right)$ \\
\hline Water & 1000 & 72.2 & 1.0 & $69.0 \pm 1.2$ \\
\hline $\begin{array}{l}\text { Aqueous solution: } \\
\text { PVP 3\% (wt.\%) }\end{array}$ & 1002 & 63.6 & 1.3 & $62.8 \pm 4.3$ \\
\hline $\begin{array}{l}\text { Aqueous solution: } \\
\text { PVP 13\% (wt.\%) }\end{array}$ & 998 & 53.8 & 3.1 & $63.8 \pm 4.7$ \\
\hline $\begin{array}{l}\text { Aqueous solution: } \\
\text { HPMC } 0.5 \% \text { (wt.\%) }\end{array}$ & 986 & 47.6 & 3.1 & $76.3 \pm 4.5$ \\
\hline $\begin{array}{l}\text { Aqueous solution: } \\
\text { HPMC 1\% (wt.\%) }\end{array}$ & 993 & 47.1 & 8.1 & $79.0 \pm 4.8$ \\
\hline $\begin{array}{l}\text { Aqueous solution: } \\
\text { HPMC 3\% (wt.\%) }\end{array}$ & 1004 & 47.3 & 117 & $82.2 \pm 5.0$ \\
\hline Powder properties & $\begin{array}{l}\mathrm{D}_{50}[\mu \mathrm{m}] \\
\text { (volumetric) }\end{array}$ & $\begin{array}{l}\text { Span } \\
\left(D_{90}-D_{10}\right) / D_{50}\end{array}$ & $\begin{array}{l}\text { Bulk density } \\
{\left[\mathrm{kg} / \mathrm{m}^{3}\right]}\end{array}$ & $\begin{array}{l}\text { True density } \\
{\left[\mathrm{kg} / \mathrm{m}^{3}\right]}\end{array}$ \\
\hline Avicel PH 105 & 20 & 1.93 & 244 & 1514 \\
\hline
\end{tabular}




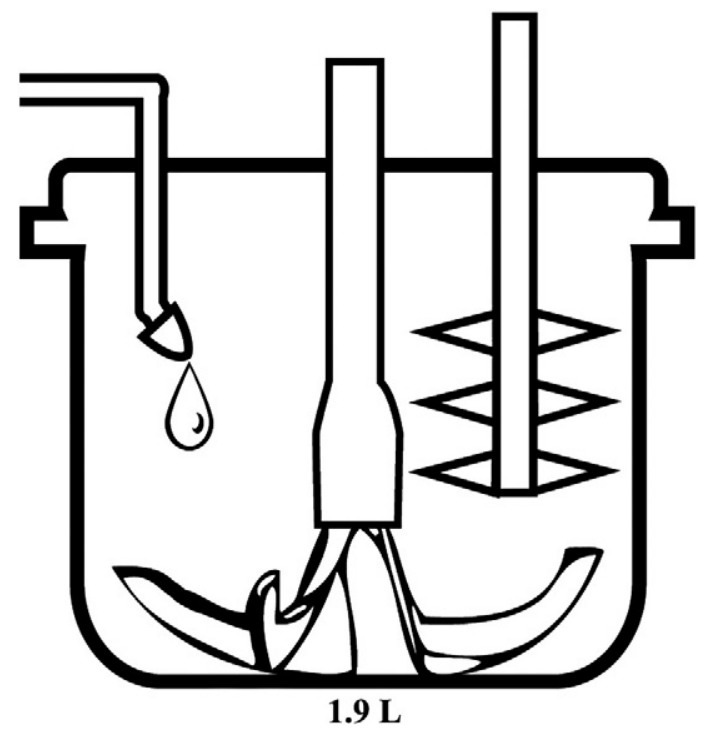

Fig. 1. Schematic representation of the Mi-Pro bowl.

carried out twice. The dried granules were sieved and 15 size fractions were collected. Weight mean diameter was determined according to:

Meandiameter $: \mathrm{d}_{\mathrm{pm}}=\frac{\sum_{i} f_{i} d_{p i}}{\sum_{i} f_{i}}$

Where $f_{i}$ is the particle mass fraction of size interval $i, d_{p i}$ is the mean diameter of size interval $i(\mu \mathrm{m})$. The sieving results led us to define three characteristic granule classes: fine (corresponding to the initial powder with granule diameters and dry agglomerates inferior to $200 \mu \mathrm{m}$ ), intermediate (weak granules with diameters between $200 \mu \mathrm{m}$ and $800 \mu \mathrm{m}$ ) and coarse (strong, dense granules with diameters greater than $800 \mu \mathrm{m}$ but smaller than $5 \mathrm{~mm}$ ). Granules exceeding $5 \mathrm{~mm}$ were defined as lumps.

Kinetic results are expressed in function of the fraction added liquid to initial dry powder mass named liquid to solid ratio:

\section{L / SRatio $=$ Added Liquid Mass $[\mathrm{kg}]$ / Initial Powder Mass $[\mathrm{kg}](\%)$}

Liquid addition rate was calculated as the amount of binder corresponding to the optimum $\mathrm{L} / \mathrm{S}$ ratio for the studied powder and

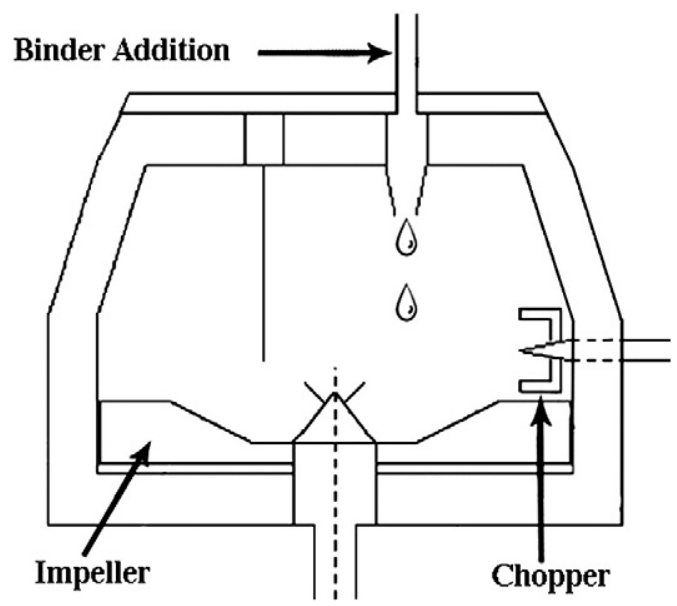

Fig. 2. Diosna P1-6 high shear mixer. liquid binder over a period of $12 \mathrm{~min}$. For instance for the granulation of $120 \mathrm{~g} \mathrm{MCC}$ in the Mi-Pro and an optimum L/S ratio of $100 \%$ a liquid addition rate of $10 \mathrm{ml} / \mathrm{min}$ has been obtained. As shown by Knight et al. [15] a gradual liquid addition leads to a more uniform distribution of the binder.

\subsubsection{The Diosna P1-6 $6^{\circledR}$ high shear mixer}

The influence of mixer design has been studied by carrying out experiments on a 6 L capacity Diosna HSM (Fig. 2). The Diosna HSM is equipped with a three-bladed impeller and a tulip-form chopper. Binder addition is realized using a Masterflex Easy-Load II pump through the top of the bowl. Granule size analysis is identical to the one described for the Mi-Pro HSM.

\subsection{Methods}

\subsubsection{The mixer torque rheometer}

Characterization of binder powder interactions was achieved using a mixer torque rheometer (Model MTR, Caleva Ltd, Dorset, England) measuring the impeller torque as binder was added to the powder. The mixer torque rheometer measures two values in function of time and added liquid: the mean torque and the amplitude of the torque oscillations or torque range as described by Rowe et al. [16]. The mean torque is equivalent to the resistance of the wet mass to mixing and allows the monitoring of the different states of saturation of the agglomerate. The torque range gives a measure of the recorded signals standard deviation and when its peak occurs earlier than the torque peak it can give an indication as to the presence of the system in the funicular saturation stage. In this study the analysis of the torque range however didn't allow us to provide additional insight since it increased and decreased with the recorded torque signal.

The dry powder was mixed in the rheometer for $30 \mathrm{~s}$ in order to obtain the baseline response. The quantity of dry powder was selected so as to cover the mixing blades which led to a volumetric fill ratio of about $40 \%$. The binder was added by the multiple addition method. After each addition the wet mass is mixed and at the end of the mixing period a mean torque value is stored so that each point on the torque curve corresponds to an addition and thus to a new saturation value of the wet mass. The torque values are expressed as normalized torque taking into account the initial powder mass. For all our experiments on the mixer torque rheometer a target mixing time of 10 min has been sought in order to ensure the good distribution of the binder in the powder bed. This was done by adjusting the added binder quantity for each addition so that at the end of the mixing time the system would have undergone the change from dry product to an almost liquid paste.

The MTR also allows the study of the wet mass consistency. A fresh (wet) granules sample obtained at the end of the granulation in the high shear mixer was introduced in the MTR and mixed for $480 \mathrm{~s}$. The wet granules are deformed under the action of the impellers and torque values evolve to a constant value named wet mass consistency.

\subsubsection{Dry granule strength}

A Texture Analyser XT plus from Stable MicroSystems has been used in order to asses dry granule strength by single granule uniaxial compression tests, equipped with a $5 \mathrm{~kg}$ load cell. Single granules $(n=20 \div 30$ granules for each binder type) were compressed with a stainless steel probe with a diameter of $6 \mathrm{~mm}$. Pictures were taken before and after compression. Granules tested where granules with the diameter close to the mean diameter of the granulation run. 

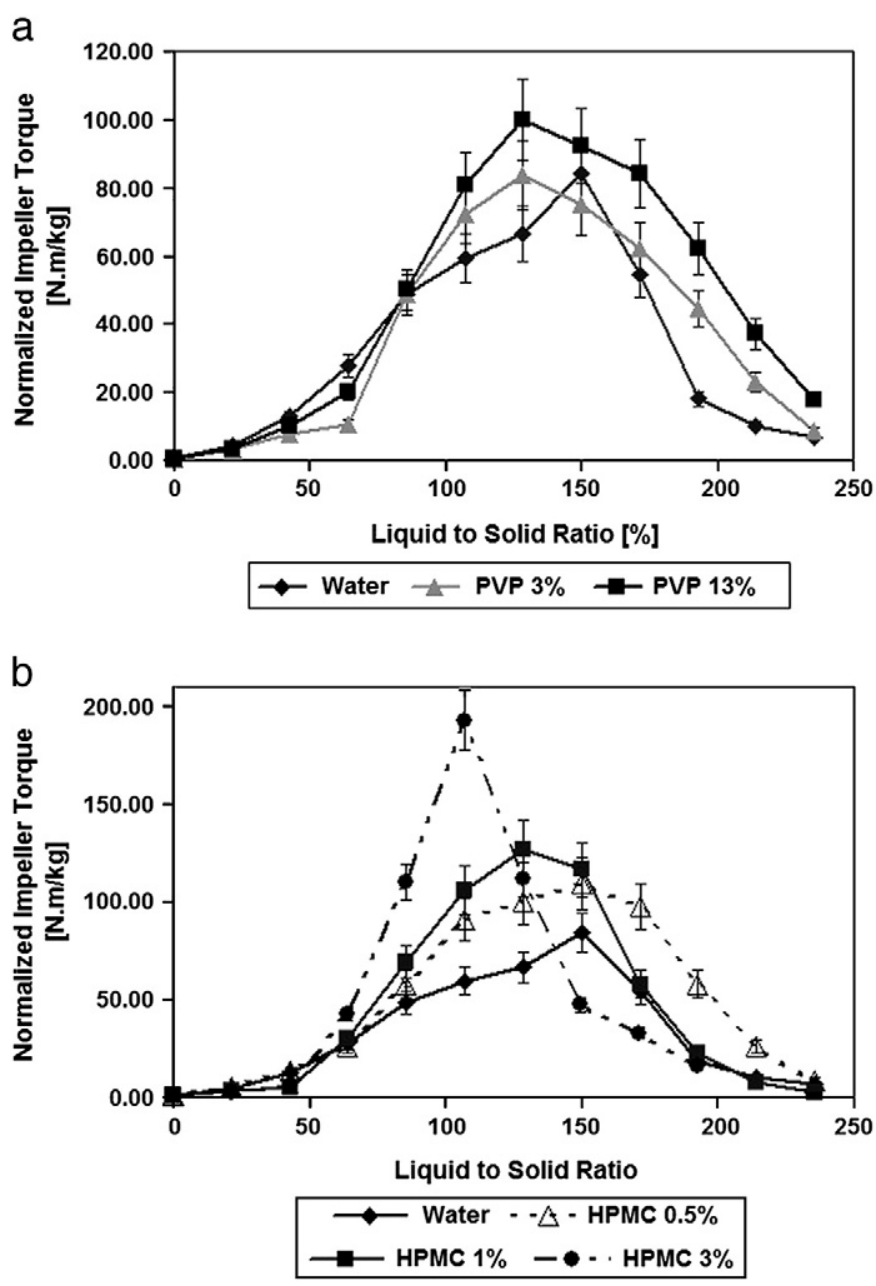

Fig. 3. Mean torque curves on the MTR for the studied binders.

Granule strength was assessed using the following equation proposed by Adams [17]:

$\sigma=4 \frac{F_{\max }}{\pi \cdot D_{g}^{2}}$

Where $F_{\max }$ is the fracture force and $\mathrm{D}_{\mathrm{g}}$ is the measured granule diameter.

Imposed velocity of the steel probe was of $0.1 \mathrm{~mm} / \mathrm{s}$ while data recording began when observing a force superior to $0.02 \mathrm{mN}$. Data sampling was done at 400 point per second and force was applied until $70 \%$ of the determined granule size has been traveled by the steel probe or until the maximum force that could be applied by the machine had been reached. From the compression curve, parameters like the compression energy or Young modulus [13] can also

Table 2

Peak torque and corresponding L/S ratio for the studied aqueous solutions mixed by multiple addition method with MCC Avicel 105 on the MTR.

\begin{tabular}{lcl}
\hline Binder type & Peak torque $[\mathrm{N} \mathrm{m} / \mathrm{kg}]$ & $\begin{array}{l}\text { L/S ratio corresponding } \\
\text { to the peak torque [\%] }\end{array}$ \\
\hline Water & $84.3 \pm 4.3$ & 150.0 \\
PVP 3\% & $83.6 \pm 4.8$ & 128.5 \\
PVP 13\% & $100.1 \pm 5.1$ & 128.5 \\
HPMC 0.5\% & $109.3 \pm 5.2$ & 150.0 \\
HPMC 1\% & $126.5 \pm 5.3$ & 128.5 \\
HPMC 3\% & $192.9 \pm 6.2$ & 107.0 \\
\hline
\end{tabular}
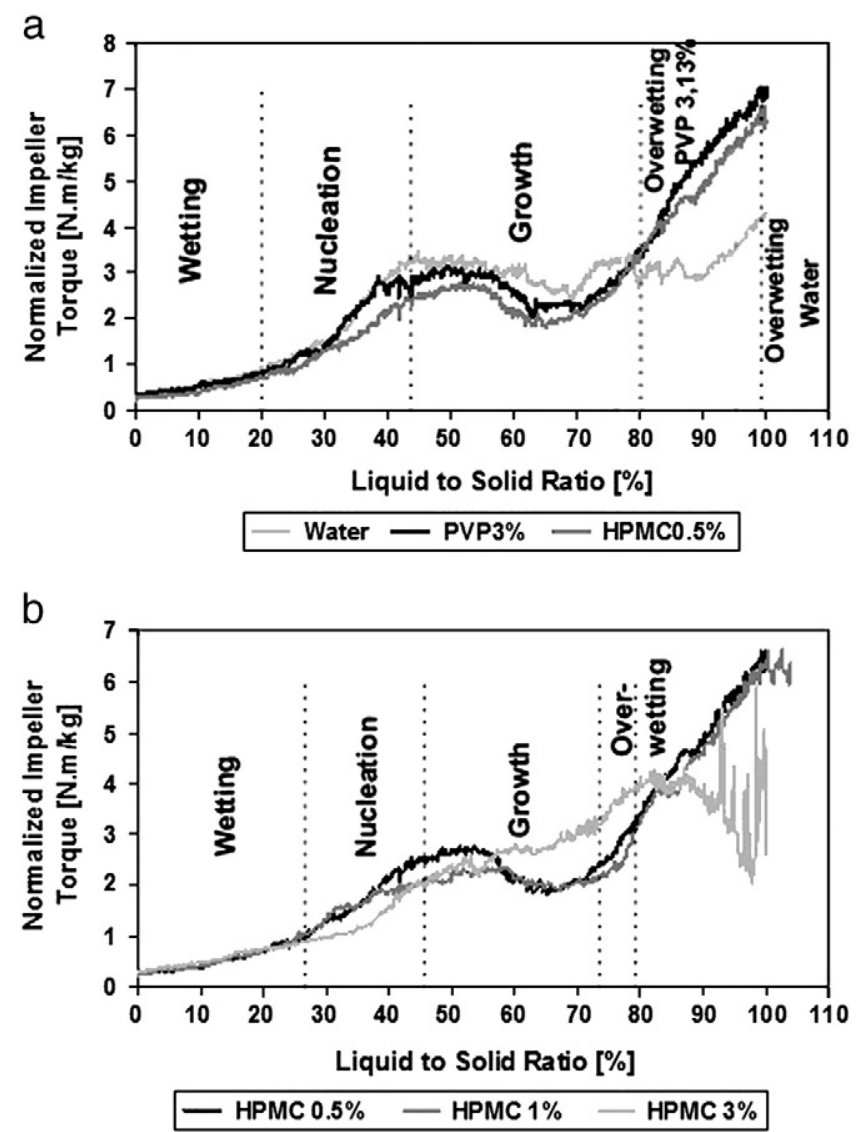

Fig. 4. Representative torque curves for the studied binder solutions on the Mi-Pro 1.9L HSM.

be obtained. The energy required to be transmitted to the granule in order to induce macroscopic failure can been calculated from the area under the force displacement curve and thus allows taking into account not just the peak force but also the deformations taking place up to the peak. However for the studied granules evolution of granule strength and compression energy presented a very similar evolution.

\section{Results and discussion}

\subsection{Rheological properties of the powder-binder couple}

Fig. 3 shows the obtained torque curves on the MTR by the method of multiple liquid additions. As discussed in our previous results [18] the peak torque on the MTR for the case of microcrystalline cellulose indicates the capillary state which in the Mi-Pro HSM corresponds to the granules uniting into a single paste like mass showing a maximum torque for the same L/S ratios. However when used comparatively to asses binder suitability we can observe similar behavior and cohesion for water and PVP 3\% solution (Fig. 3a). PVP $13 \%$ develops a slightly higher cohesion than both water and PVP $3 \%$ while using both PVP $3 \%$ and PVP $13 \%$ as binders lowers the L/S ratio necessary for achieving the capillary state. The HPMC 0.5\% and 1\% binder solutions are showing higher cohesions than those obtained with water while an abrupt increase in torque is observed for the more viscous binder solution of HPMC 3\% (Fig. 3b) indicating a greater risk in over wetting the powder bed. The maximum developed cohesion is obtained for the HPMC 3\% polymeric binder solution. Table 2 presents peak torque and corresponding $\mathrm{L} / \mathrm{S}$ ratio for the studied aqueous solutions mixed by multiple addition method with MCC Avicel 105 on the MTR. 

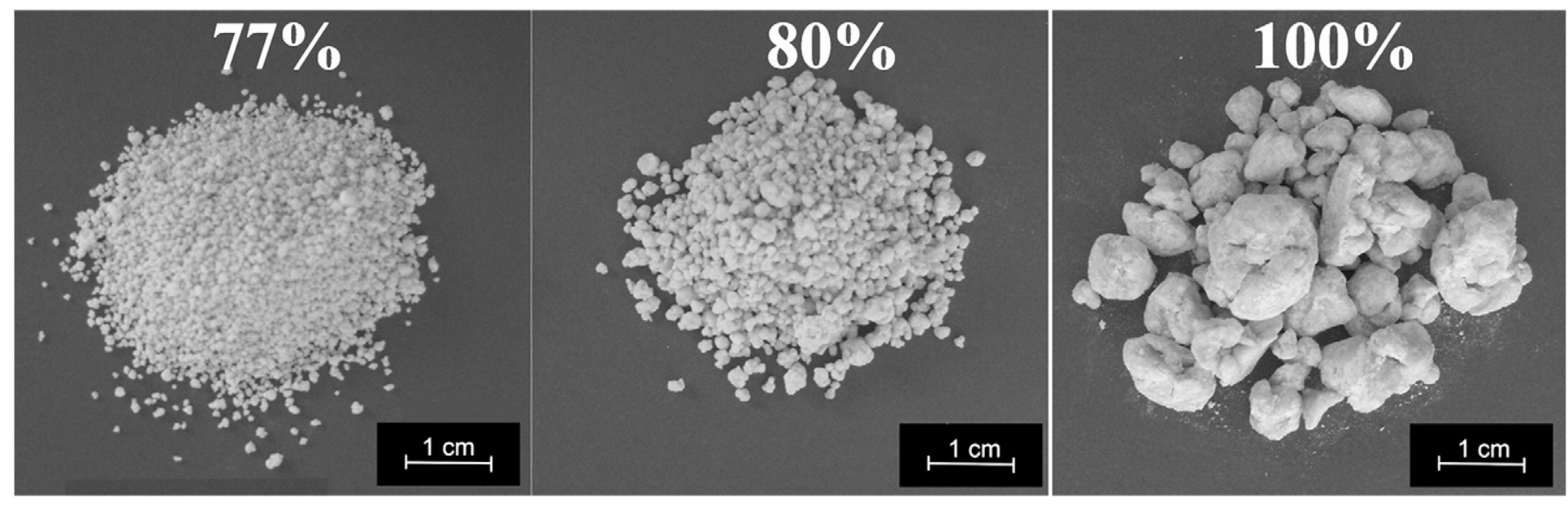

Fig. 5. Final granules obtained in the Mi-Pro 1.9L HSM for different L/S ratios of HPMC $3 \%$.

\subsection{Granulation kinetics for the studied binders}

Torque curves recorded on the Mi-Pro high shear mixer (Fig. 4) have shown that different binder types present different liquid requirements. The initial wetting and nucleation phases are similar for all binders while the extent of the growth (plateau region) varies. For water a quantity of liquid equivalent to approximately $100 \% \mathrm{~L} / \mathrm{S}$ ratio is necessary while even the slightest addition of a polymer (PVP $3 \%$ ) lowers the optimum L/S ratio (Fig. 4a). Low viscosity polymeric binders like PVP3\% and PVP 13\%, HPMC 0.5\% and HPMC 1\% show similar torque curves with the plateau phase ending at about 75 to 83\% L/S ratios, lower than the $83-91 \% \mathrm{~L} / \mathrm{S}$ ratio observed when granulating with water. The torque curve for PVP $13 \%$ is not presented in Fig. 4a because its evolution is nearly identical to the one obtained for PVP $3 \%$. It was also observed that both water and the PVP solutions give shorter wetting stages $(20-22 \% \mathrm{~L} / \mathrm{S}$ ratio) than the HPMC solutions (27\% L/S ratio). For high viscosity binders like HPMC $3 \%$ we have observed even shorter growth zones with values around $75-78 \%$ L/S ratio (Fig. 4b). The optimum liquid requirement corresponds largely with the end of the plateau. For water more water can be added as to maximize the yield in coarse granules without endangering over wetting. For the aqueous polymer solutions the end of the plateau is the maximum safe value for the $\mathrm{L} / \mathrm{S}$ ratio as the polymer film on the granule surface favors coalescence and over wetting can easily occur. When granulating with HPMC $3 \%$ granulation has to be closely watched because the a
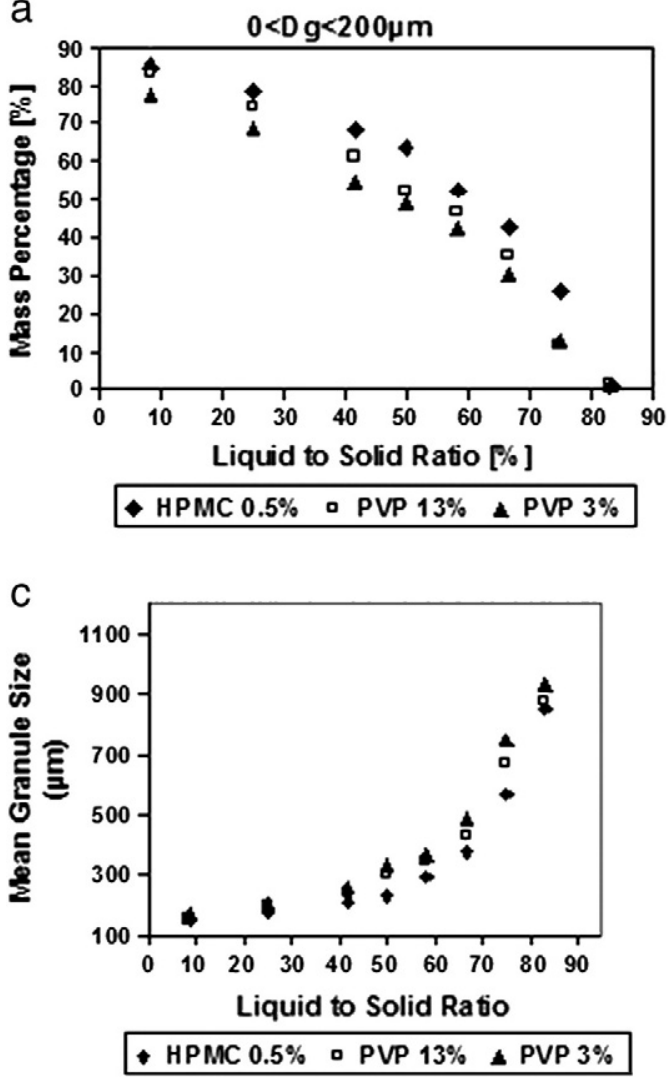

b

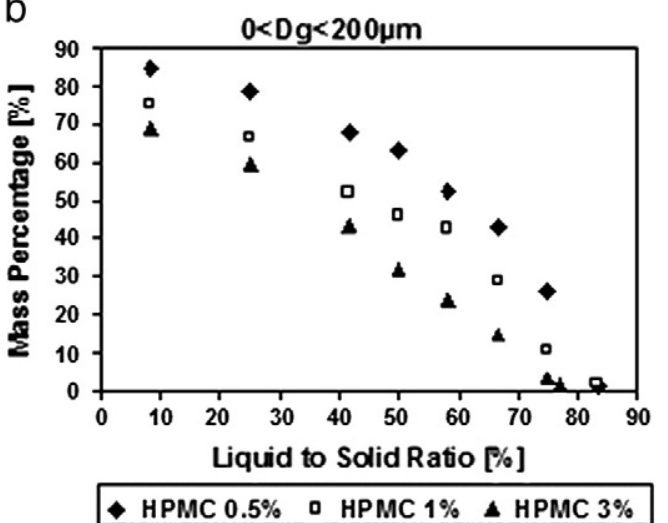

d

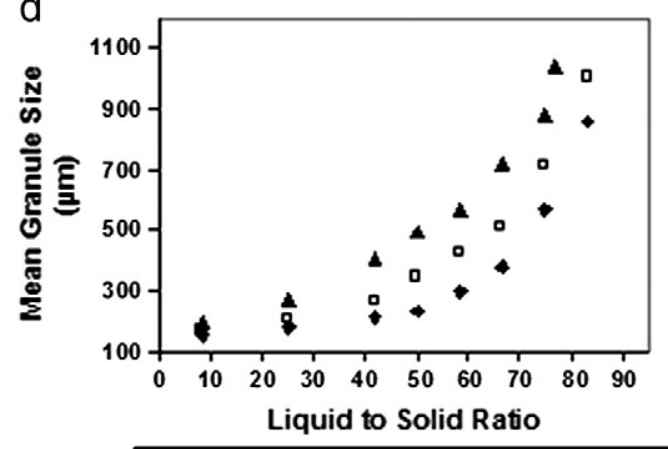

Fig. 6. Evolution of fine particles(a,b) and mean granule size(c,d) for the wet granulation runs with different binders. 
Table 3

Wet granulation characteristic results for the different binders employed.

\begin{tabular}{llclc}
\hline Binder type & Wa $[\mathrm{mN} / \mathrm{m}]$ & $\mathrm{Ca}^{*}$ & $\begin{array}{l}\text { Optimum L/S } \\
\text { ratio }[\%]\end{array}$ & $\begin{array}{l}\text { Mean diameter } \\
{[\mu \mathrm{m}][ \pm 10 \%]}\end{array}$ \\
\hline Water & 98.1 & 0.058 & 100 & 810 \\
PVP 3\% & 92.8 & 0.082 & 83 & 936 \\
PVP 13\% & 77.5 & 0.235 & 83 & 877 \\
HPMC 0.5\% & 58.9 & 0.307 & 83 & 857 \\
HPMC 1\% & 56.1 & 0.842 & 83 & 1006 \\
HPMC 3\% & 53.7 & 12.76 & 77 & 1039 \\
\hline
\end{tabular}
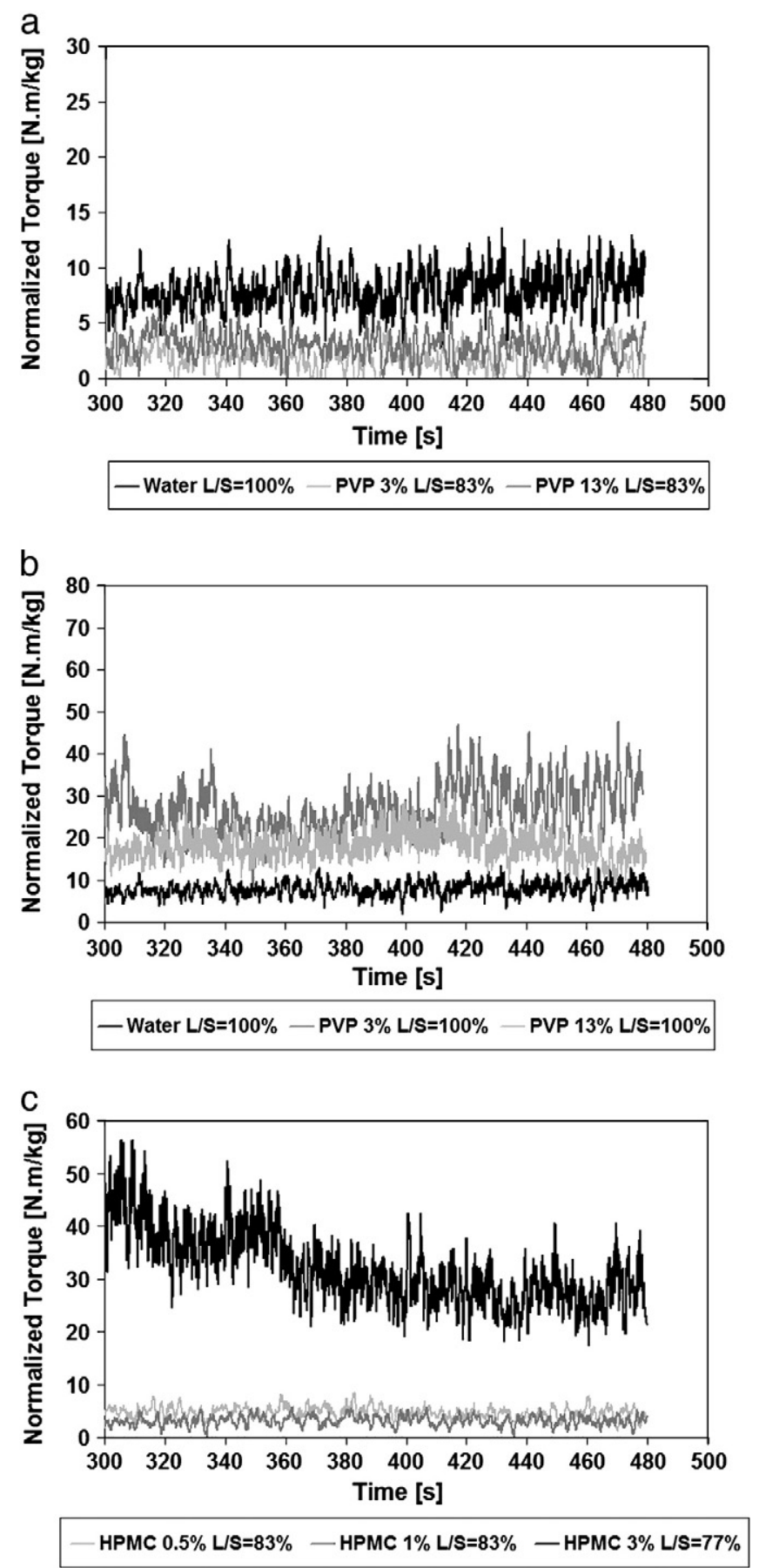

Fig. 7. Typical wet mass consistency evolutions for the studied binders.
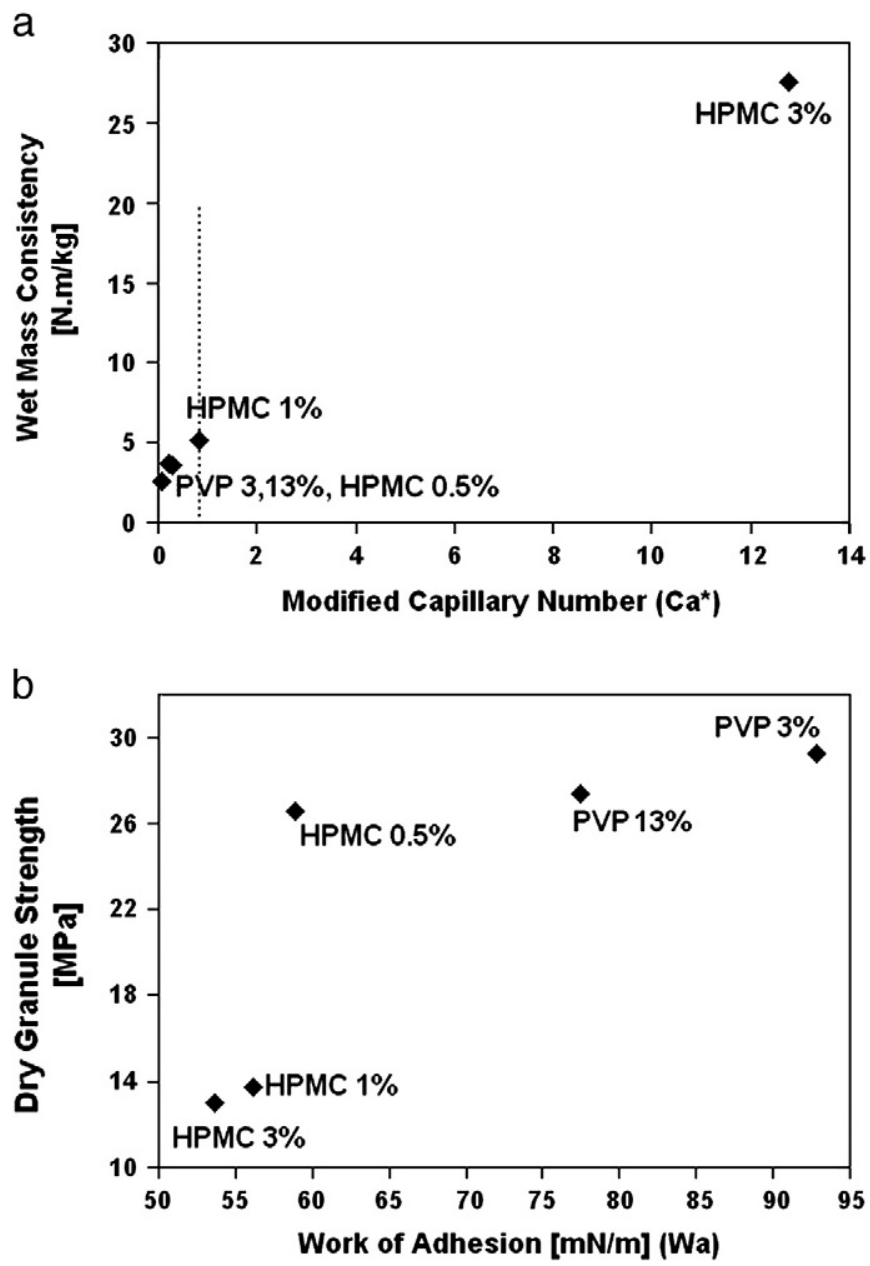

Fig. 8. Evolution of wet mass consistency vs $\mathrm{Ca}^{*}$ (a) and dry granule strength vs work of adhesion (b).

passage from granules to paste occurs more rapidly for the more viscous binders and over wetting can easily occur (Fig. 5).

From the granule growth kinetics point of view (Fig. 6) we have observed that:

- for low viscosity binders like PVP 3\%, PVP 13\% and HPMC 0.5\% for the same $\mathrm{L} / \mathrm{S}$ ratio the interfacial forces are dominant (Fig. 6a and c). The fine fraction decreases more rapidly and mean granule size increases with increasing work of adhesion in the order PVP $3 \%>$ PVP $13 \%>$ HPMC $0.5 \%$ as predicted from the wettability measurements,

- for different concentrations of HPMC increasing viscosity accelerates growth in the order HPMC $3 \%>$ HPMC $1 \%>$ HPMC $0.5 \%$ (Fig. $6 \mathrm{~b}$ and d),

- while the torque curve shows little differences in the transitions between the wetting and nucleation stages the evolution of the fines particles class (Fig. 6a and b) are more indicative for differences between the different aqueous solution binders,

- the evolution of the mean granule size (Fig. $6 c$ and d) does not allow us to interpret difference between the different binders up to $50 \% \mathrm{~L} / \mathrm{S}$ ratio for the low viscosity binders and up to $25 \%$ for the higher viscosity binders.

The accelerated growth for more viscous binders, anticipated from the torque curves which indicated lower $\mathrm{L} / \mathrm{S}$ ratios in order to achieve optimum liquid requirement, can be explained by the longer penetration time (as defined by Denesuk et al. [19]) of the more viscous binders in the granules that form a film on the surface leading to successful coalescence between granules. This observation is further confirmed by 
Table 4

Dry granule strength and wet mass consistency as a function of binder used.

\begin{tabular}{llcllc}
\hline $\begin{array}{l}\text { Binder } \\
\text { type }\end{array}$ & $\begin{array}{l}\text { Wa } \\
{[\mathrm{mN} / \mathrm{m}]}\end{array}$ & Ca* & $\begin{array}{l}\text { Mean diameter } \\
{[\mu \mathrm{m}][ \pm 10 \%]}\end{array}$ & $\begin{array}{l}\text { Dry granule } \\
\text { strength [MPa] }]\end{array}$ & $\begin{array}{l}\text { Wet mass } \\
\text { consistency } \\
{[\mathrm{N} \mathrm{m} / \mathrm{kg}]}\end{array}$ \\
\hline Water & 98.1 & 0.058 & 810 & $37.0 \pm 4.7$ & 8.2 \\
PVP 3\% & 92.8 & 0.082 & 936 & $29.2 \pm 4.3$ & 2.6 \\
PVP 13\% & 77.5 & 0.235 & 877 & $27.4 \pm 3.1$ & 3.7 \\
HPMC 0.5\% & 58.9 & 0.307 & 857 & $26.6 \pm 4.8$ & 3.55 \\
HPMC 1\% & 56.1 & 0.842 & 1006 & $13.7 \pm 2.7$ & 5.15 \\
HPMC 3\% & 53.7 & 12.76 & 1039 & $13.0 \pm 2.4$ & 27.6 \\
\hline
\end{tabular}

the higher wet mass consistencies recorded with increasing viscosity. Table 3 shows the values for the work of adhesion, the modified capillary number, optimum L/S ratio, and the corresponding dry mean granule size at the end of granulation. The optimum L/S ratios are a result of torque curve analysis as well as observed granule growth kinetics by sieving of samples. Granulation with pure water is considered a special case as it demands much more liquid to granulate and interpretations on granule growth kinetics or final granule properties are hard to correlate with just differences in physico-chemical properties between binder solutions.

\subsection{Wet mass consistency and granule strength}

Samples taken at the end of each granulation run of the Mi-Pro for different binder and $\mathrm{L} / \mathrm{S}$ ratios have been mixed in the MTR in order to determine wet mass consistency. This approach is based on the presumption that the intense mixing in the MTR can transform the
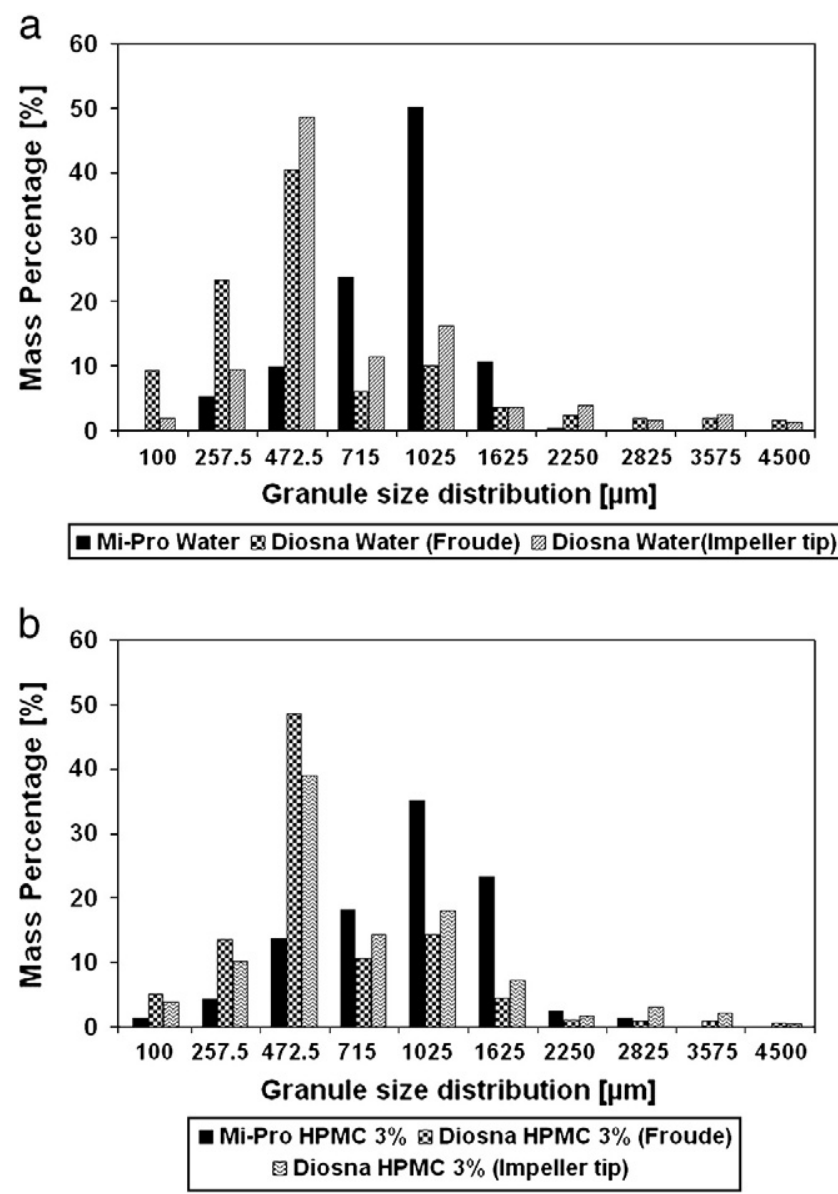

Fig. 9. Granule size distributions on the studied high shear mixers for water (a) and HPMC 3\% (b). granules to a homogenous mass. Fig. 7 shows some typical wet mass consistency results from which the mean value has been calculated. At the determined optimum liquid requirements we can observe water giving a higher wet mass consistency then both PVP solutions (Fig. 7a). However bringing the PVP binder solutions to the same L/S ratio as water (100\%) leads to higher wet mass consistencies (Fig. 7b). For the HPMC solutions we can observe that only a high increase in viscosity as for HPMC 3\% gives a much larger wet mass consistency compared to both HPMC 1\% and HPMC 0.5\% (Fig 7c). When regrouping the evolution of wet mass consistency as a function of the modified capillary number (Fig. 8a) we can observe the following regions: for $\mathrm{Ca}^{*}<0.8$ a weak change in wet mass consistency is observed followed by a seemingly exponential growth with increasing $\mathrm{Ca}^{*}$, although additional points would be necessary to validate this assumption.

The mean dry granule strength was evaluated for granules with diameters between 1 and $1.25 \mathrm{~mm}$ considered as representative for our granulation runs in respect to the final mean granule sizes and granule size distributions. Granule shape has been analyzed by the Malvern PharmaVision 830 Automated Microscopy System. Roundness is a measurement relating length to width and presenting values in the range of 0 to 1 . A perfect circle would present a roundness of 1 while a needle shaped particle would have a roundness close to 0 . The roundness is determined typically using the equation:

Roundness $=\frac{4 \pi A_{g}}{P_{g}^{2}}$

Where $A_{g}$ is the measured area and $P_{g}$ is the perimeter of the granules. The zoom objective was used at the 0.5 position at which it presents a resolution of $18 \mu \mathrm{m}$, a depth of field of $11 \mu \mathrm{m}$, a field of view of $4722 \times 6166 \mu \mathrm{m}$ and can analyze granules in the size range of 45 to $1908 \mu \mathrm{m}$. The resulting roundness mean value for a distribution by number was of $\sim 0.75$ to 0.85 for the obtained granules. In the absence of a spheronization protocol the obtained values show a good roundness allowing us to use Eq. 5 for granule strength measurements.

In order to assess the influence of variables that describe binder properties like viscosity and liquid surface tension and solid liquid interaction like the contact angle we calculated the values for work of adhesion and a modified capillary number. Table 4 also presents the measured values for wet mass consistency and dry granule strength.

Tables 3 and 4 show the results in terms of optimum L/S ratio, mean granule size, wet mass consistency and dry granule strength. Two situations can be identified:

- for the polymeric solutions with $\mathrm{Ca}^{*}<0.8$ a reduction of Wa leads to a reduction in mean granule size as well as a slight reduction of granule strength while the optimum $\mathrm{L} / \mathrm{S}$ ratio remains constant

- for polymeric solutions with $\mathrm{Ca}^{*} \geq 0.8$ we observe slightly larger mean granule sizes, lower granule strengths and an increase in wet mass consistency.

Table 5

Dry granule strength and mean granule size on the investigated mixers.

\begin{tabular}{llc}
\hline $\begin{array}{l}\text { Binder type and } \\
\text { impeller speed }\end{array}$ & $\begin{array}{l}\text { Dry granule } \\
\text { strength }[\mathrm{MPa}]\end{array}$ & $\begin{array}{l}\text { Mean granule } \\
\text { size }[\mu \mathrm{m}]\end{array}$ \\
\hline Mi-Pro & & \\
Water $(800 \mathrm{rpm})$ & $37.0 \pm 4.7$ & 1039 \\
HPMC 3\% (800 rpm) & $13.0 \pm 2.4$ & \\
& & 840 \\
Diosna & & 715 \\
Water $(460 \mathrm{rpm})$ & $29.5 \pm 5.0$ & 780 \\
Water $(605 \mathrm{rpm})$ & $24.1 \pm 3.5$ & 670 \\
HPMC 3\% $(460 \mathrm{rpm})$ & $10.6 \pm 3.1$ & \\
HPMC 3\% (605 rpm) & $10.8 \pm 2.5$ & \\
\hline
\end{tabular}




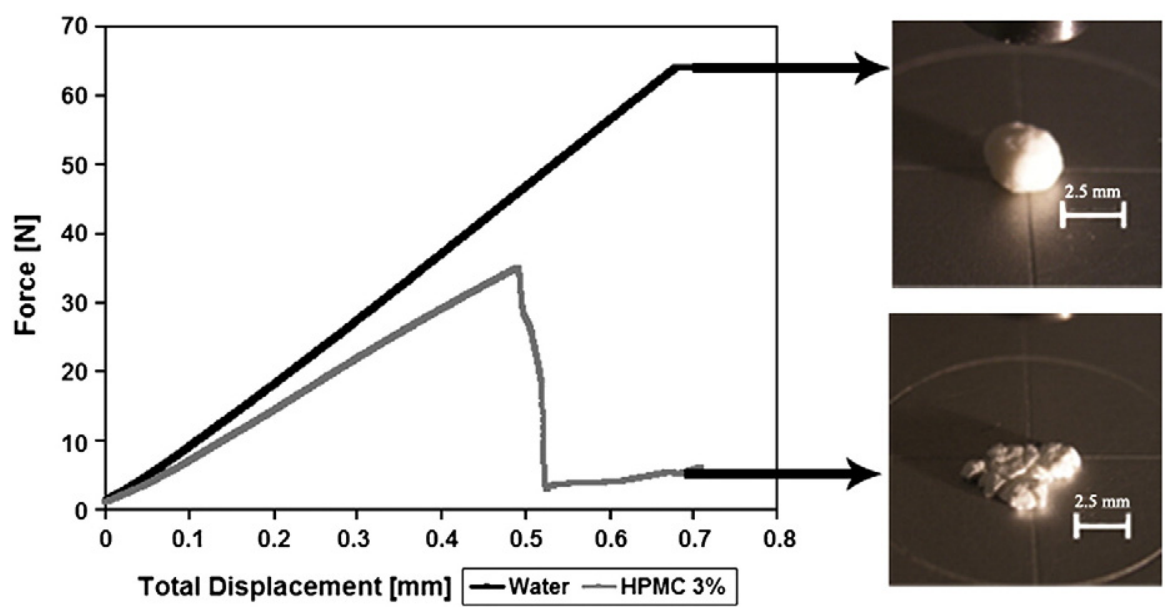

Fig. 10. Typical load displacement curves for large granules obtained from the Diosna HSM using constant impeller tip speed as scale-up rule when using water and HPMC $3 \%$ as binders.

These results seem to be in line with the results obtained by Benali et al. [11] with the decrease in the boundary condition (0.8 vs. 1$)$ most probably affected by the lower viscosity necessary to agglomerate finer particles ( $20 \mu \mathrm{m}$ mean granule size for Avicel 105 versus $60 \mu \mathrm{m}$ mean particle size for Avicel 101) as also shown by Keningley et al. [4].

The dry granule strength measurements show that granule strength increases with increasing work of adhesion (Fig. 8b) while also showing that the dry granule strength for the more viscous binders is largely inferior to the low viscosity binders.

\subsection{Effect of mixer design}

As discussed by K. Giry et al. [20] in practice switching from one granulation equipment to another may be necessary to comply with available production equipment. Granulation runs for a low viscosity and a high viscosity binder has been carried out on the $6 \mathrm{~L}$ Diosna HSM. While the switch from a 1.9 to a $6 \mathrm{~L}$ high shear mixer does not represent a huge step in manufacturing capacity the Diosna high shear mixer family can go in a similar geometry up to $60 \mathrm{~L}$ at laboratory scale and up to $1250 \mathrm{~L}$ at production plant scale. Without carrying out an extensive characterization of granulation on the Diosna we chose to use two of the more commonly employed scale-up rules, namely:constant impeller tip speed,

$\omega=\frac{N}{60} \cdot \pi \cdot D$

-constant Froude number,

$\mathrm{Fr}=\frac{\mathrm{N}^{2} \cdot \mathrm{D}}{\mathrm{g}}$

Where $\mathrm{N}$ is the impeller speed, $\mathrm{D}$ the impeller diameter and $\mathrm{g}$ the gravitational acceleration constant.

Applying these rules gave two corresponding impeller speeds on the Diosna:

- $460 \mathrm{rpm}$ for constant impeller tip speed,

- 605 rpm for constant Froude number.

We chose the two binders solution with significantly different properties: water with low viscosity and high binder surface tension and HPMC $3 \%$ with a high binder viscosity and a lower binder surface tension. The same fill ratios, granulation time, optimum L/S ratios have been kept while using the same manually controlled drop by drop pump on both high shear mixers. The chopper on the Diosna has been operated at $500 \mathrm{rpm}$ while the chopper on the Mi-Pro was turning at $3000 \mathrm{rpm}$.

Mean granule size analysis (Fig. 9a and b) shows that both scale-up criteria yield lower mean granule sizes on the Diosna. The constant impeller tip speed yields a closer result in terms of granule sizes, it shears and impacts less, causing breakage to a lesser extent than when keeping the Froude number constant.

The Diosna dry granule strength (Table 5 ) shows greater values for granules where water was used as binder than where HPMC 3\% was used. While dry granule strength has been determined for the same size interval as in the previous experiments we also tested some granules in the $2.5-3 \mathrm{~mm}$ range. Fig. 10 shows the load-displacements curve for two larger granules $(2.5-3.15 \mathrm{~mm})$ for water and HPMC. We observe that the water granulated granule doesn't break reaching the limits of the testing machine's maximum force while the HPMC 3\% granules is being crushed.

Increasing impeller speed reduces dry granule strength on the low viscosity binder however on the high viscosity binder little variation in dry granule strength is observed. Recently Mangwandi et al. [21] showed on the granulation of lactose with a high (HPC solution 8\%, viscosity of $150 \mathrm{mPa} \mathrm{s}$ ) and a low viscosity binder (distilled water) that increasing impeller speed can increase granule strength, Young's modulus and yield strength for the high viscosity binder and decrease for the low viscosity binder. Although only the viscosity aspect is discussed this result also underlines the importance of binder-substrate interaction in regards to granule strength. Granule strength compared between mixers shows lower values when granulating at the larger scale. This could be explained by the fact that at lower scales mixing is more intense and collisions between particles, bowl walls and impeller are more frequent leading to increased granule consolidation.

\section{Conclusion}

We found that torque curves can allow a good control over the granulation process allowing us to define optimum binder requirements for the different binder solutions used, essential for obtaining similar granule size distributions. Optimum liquid requirement has been found to decrease with increasing viscosity, this indicating the accelerated growth due to more successful coalescence between granules, however this slower penetration of the binder has two very different effects on granule strength: it yields higher wet mass consistencies as the viscous binder is still at granule surface and sticks easily to the mixer torque rheometer blades but doesn't offer a great inner strength which is apparent from the dry granule uniaxial compression tests where the more viscous binders show lower granule strength. Recorded torque curves as well as granule growth kinetics and dry granule strength 
measurements show that granulation, at low viscosities, is dependent on the work of adhesion. The use of the capillary viscous number allowed us to define the boundaries for which the work of adhesion is the dominant parameter $\mathrm{Ca}^{*}<0.8$ and for which the viscosity is the controlling parameter $\mathrm{Ca}^{*} \geq 0.8$, although additional testing for the latter case would be needed.

Alternative means of measuring wet granule strength are also imagined. For the study of mixer design additional testing on the Diosna scale would be necessary with the goal of obtaining similar granule size distributions on both scales.

\author{
List of symbols \\ $\mathrm{d}_{\mathrm{pi}} \quad$ mean diameter of size interval $\mathrm{i}(\mathrm{m})$ \\ $\mathrm{d}_{\mathrm{pm}} \quad$ mean diameter $(\mathrm{m})$ \\ $\mathrm{D} \quad$ impeller diameter $(\mathrm{m})$ \\ $\mathrm{D}_{\mathrm{g}} \quad$ granule diameter $(\mathrm{m})$ \\ $\mathrm{f}_{\mathrm{i}} \quad$ particle mass fraction of size interval $\mathrm{i}(\% \mathrm{w} / \mathrm{w})$ \\ $\mathrm{F}_{\max } \quad$ fracture force $(\mathrm{N})$ \\ g standard gravity $\left(\mathrm{m} / \mathrm{s}^{2}\right)$ \\ $\mathrm{N} \quad$ impeller rotational speed (rpm) \\ $\mathrm{W}_{\mathrm{a}} \quad$ adhesion work $(\mathrm{N} / \mathrm{m})$ \\ $\mathrm{A}_{\mathrm{g}} \quad$ is the measured granule area $\left(\mathrm{m}^{2}\right)$ \\ $\mathrm{Pg} \quad$ is the perimeter of the granules $(\mathrm{m})$ \\ Greek symbols \\ $\gamma_{\mathrm{L}} \quad$ liquid surface tension $(\mathrm{N} / \mathrm{m})$ \\ $\theta \quad$ contact angle \\ $\mu_{\mathrm{L}} \quad$ liquid viscosity (Pa s) \\ $\rho_{\mathrm{L}} \quad$ liquid density $\left(\mathrm{kg} / \mathrm{m}^{3}\right)$ \\ $\sigma \quad$ granule strength $(\mathrm{Pa})$ \\ Adimensional numbers \\ $\mathrm{Ca}^{*} \quad$ modified capillary viscous number \\ Fr Froude number
}

\section{Acknowledgements}

The authors would like to thank Prof. Mos Barigou, Dr Taghi Miri, and Prof. Zhibing Zhang from the Department of Chemical Engineering at the University of Birmingham for facilitating the dry granule strength measurements on the Texture Analyser.

\section{References}

[1] S.M. Iveson, J.D. Litster, K. Hapgood, B.J. Ennis, Nucleation, growth and breakage phenomena in agitated wet granulation processes: a review, Powder Technol. 117 (2001) 3-39.

[2] G.I. Tardos, M.I. Khan, P.R. Mort, Critical parameters and limiting conditions in binder granulation of fine powders, Powder Technol. 94 (1997) 245-258.

[3] H.L. Leuenberger, M. Puchkov, E. Krausbacher, G. Betz, Manufacturing pharmaceutical granules: is the granulation end-point a myth, 3rd Int. Granulation Workshop, 2007 Sheffield.

[4] S. Keningley, P. Knight, A. Marson, An investigation into the effects of binder viscosity on agglomeration behaviour, Powder Technol. 91 (1997) 95-103.

[5] A. Johansen, T. Schaefer, Effects of interactions between powder particle size and binder viscosity on agglomerate growth mechanisms in a high shear mixer, Eur. J. of Pharm. Sci. 12 (2001) 297-309.

[6] P.J.T. Mills, J.P.K. Seville, P.C. Knight, M.J. Adams, The effect of binder viscosity on particle agglomeration in a low shear mixer/agglomerator, Powder Technol. 113 (2000) 140-147.

[7] C. Capes, P. Danckwerts, Granule formation by the agglomeration of damp powders. Part I: the mechanism of granule growth, Trans. Inst. Chem. Eng. 43 (1965) 116-124.

[8] S.M. Iveson, J.D. Litster, B. Ennis, Fundamental studies of granule consolidation. Part 2. Quantifying the effects of particle and binder properties, Powder Technol. 99 (1998) 243-250.

[9] M. Ritala, O. Jungersen, P. Holm, A comparison between binders in the wet phase of granulation in a high shear mixer, Drug Dev. And Ind; Pharm. 12 (1986) $1685-1700$.

[10] B.J. Ennis, G. Tardos, R. Pfeffer, A microlevel-based characterization of granulation phenomena, Powder Technol. 65 (1991) 257-272.

[11] M. Benali, V. Gerbaud, M. Hemati, Effect of operating conditions and physicochemical properties on the wet granulation kinetics in high shear mixer, Powder Technol. 190 (2009) 160-169.

[12] S. Malamataris, S. Kiortsis, Wettability parameters and deformational behavior of powder liquid mixes in the funicular agglomeration phase, Int. J. Pharm. 154 (1997).

[13] T. M. Chitu, Granulation humide des poudres cohésives: Rhéologie, Mécanismes de croissance et Tenue mécanique des granules, PhD Thesis (2009), Institut National Polytechnique de Toulouse.

[14] H. Leuenberger, Granulation: new techniques, Pharm. Acta Helv. (1982) 72-82 $57 / 3$.

[15] P.C. Knight, T. Instone, J.M.K. Pearson, M.J. Honslow, Powder Technol. 97 (1998) 246-257.

[16] R.C. Rowe, Characterization of wet powder masses using a mixer torque rheometer. 4. Effect of blade orientation, Int. J. Pharm. 133 (1996) 133-138.

[17] M.J. Adams, M.A. Mullier, J.P.K. Seville, Agglomerate strength measurement using a uniaxial confined compression test, Powder Technol. 78 (1994) 5-13.

[18] T.M. Chitu, M. Benali, D. Oulahna, M. Hemati, Prediction of granulation mechanisms in high shear mixing granulation for soluble and insoluble substrates using rheological characterization and moisture sorption isotherms, 18th Int Congress of Chemical and Process Engineering CHISA, 2008.

[19] M. Denesuk, G.L. Smith, B.J.J. Zelinski, N.J. Kreidl, D.R. Uhlmann, Capillary penetration of liquid droplets into porous materials, J. Colloid Interface Sci. 158 (1993) 114-120.

[20] K. Giry, M. Genty, M. Viana, P. Wüthrich, D. Chulia, Multiphase versus single pot granulation process: influence of process and granulation parameters on granules properties, Drug Dev. Ind. Pharm. 32 (5) (2006) 509-530.

[21] C. Mangwandi, M.J. Adams, M.J. Hounslow, A.D. Salman, Effect of impeller speed on mechanical properties of granules in high shear granulation, 9th International Symposium on Agglomeration, 2009 Sheffield. 